\title{
Microwave coagulation therapy: the future is quite rosy
}

\author{
Paola Tombesi, Francesca Di Vece, Sergio Sartori \\ Department of Medical, Section of Interventional Ultrasound, St. Anna Hospital, 44100 Ferrara, Italy
}

Address for correspondence:

Prof. Sergio Sartori, Department of Medical, Section of Interventional Ultrasound, St. Anna Hospital, Via A. Moro, 44100 Ferrara, Italy.

E-mail: srs@unife.it

Received: 29-10-2015, Accepted: 09-11-2015

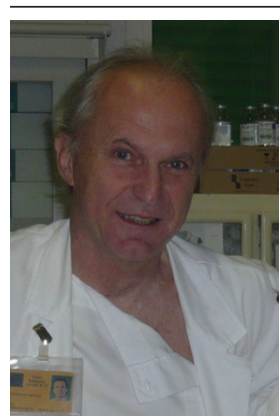

Prof. Sergio Sartori was born on June 22, 1954, and graduated cum laude in 1979. He is specialist in Gastroenterology and in Clinical Pharmacology, is dealing with interventional ultrasonography from 1990, and from 2002 is Chief of the Section of Interventional Ultrasound, St. Anna Hospital, Ferrara, Italy. He is author of 246 scientific papers.

\section{TO THE EDITOR}

We read with great interest the review of Guan ${ }^{[1]}$ on microwave coagulation therapy (MCT) of hepatocellular carcinoma (HCC), and we strongly agree with his conclusion that MCT has a great promise for future use, especially with further technical improvements.

In this regard, one of the main limits of MCT [which discouraged its clinical application in many western countries in favor of radiofrequency ablation (RFA)] was the back heating effect, due to reflected waves along the coaxial line. Such a drawback imposed to use large antennas and to deliver energy for a short time, achieving small ablation areas and requiring multiple insertions even in the presence of small tumors. ${ }^{[2,3]}$ Internally-cooled MCT partially reduced this problem, allowing for the increase of the ablation time and the amount of power that could be safely delivered. ${ }^{[4]}$ The introduction into the distal portion of the antenna of a choke coil was proposed to reduce back heating effects. However, this remedy caused remarkable thickening of the antenna (9-10 gauge), making the

\begin{tabular}{|l|c|}
\hline \multicolumn{3}{|c|}{ Access this article online } \\
\hline \multirow{2}{*}{$\begin{array}{l}\text { Website: } \\
\text { http://hrjournal.net }\end{array}$} & Quick Response Code \\
\hline DOI: & \\
10.4103/2394-5079.170543 &
\end{tabular}

device not suitable for percutaneous applications. ${ }^{[5]}$ In the very last years, a miniaturized device for MW confinement has been developed (Mini Choke®), that enables to minimize back heating effects using slender MW antennas and allowing for percutaneous applications (AMICA MWA System, HS Hospital Service, Aprilia, Italy). In an experimental study, this system produced thermal lesions of $6.5 \mathrm{~cm} \times 4.5 \mathrm{~cm}$ in ex vivo bovine liver by delivering $60 \mathrm{~W}$ for $10 \mathrm{~min} .{ }^{[6]} \mathrm{A}$ randomized prospective comparison of MCT and RFA reported significantly larger coagulation areas in vivo with MCT than with internally-cooled RFA, using a 16-gauge internallycooled, minichoked MCT antenna with a power output of 60-70 $\mathrm{W}$ and ablation time of $10 \mathrm{~min} .{ }^{|7|}$ Although energy delivery was underpowered with respect to the maximum power output of the system, MCT yielded ablation areas comparable to those previously reported by other authors who performed MCT using a power output of $100 \mathrm{~W}$ and a 14-gauge cooled shaft antenna without choke device. ${ }^{[8]}$ As the minichoked MWA system can also use a 14-gauge antenna with a power output of $100 \mathrm{~W}$, it is hypothesizable that ablation areas even larger than those obtained in the above-mentioned in vivo comparison between MCT and RFA could be achieved using the maximum

This is an open access article distributed under the terms of the Creative Commons Attribution-NonCommercial-ShareAlike 3.0 License, which allows others to remix, tweak, and build upon the work non-commercially, as long as the author is credited and the new creations are licensed under the identical terms.

For reprints contact: service@oaepublish.com

How to cite this article: Tombesi P, Di Vece F, Sartori S. Microwave coagulation therapy: the future is quite rosy. Hepatoma Res 2016;2:107-8. 


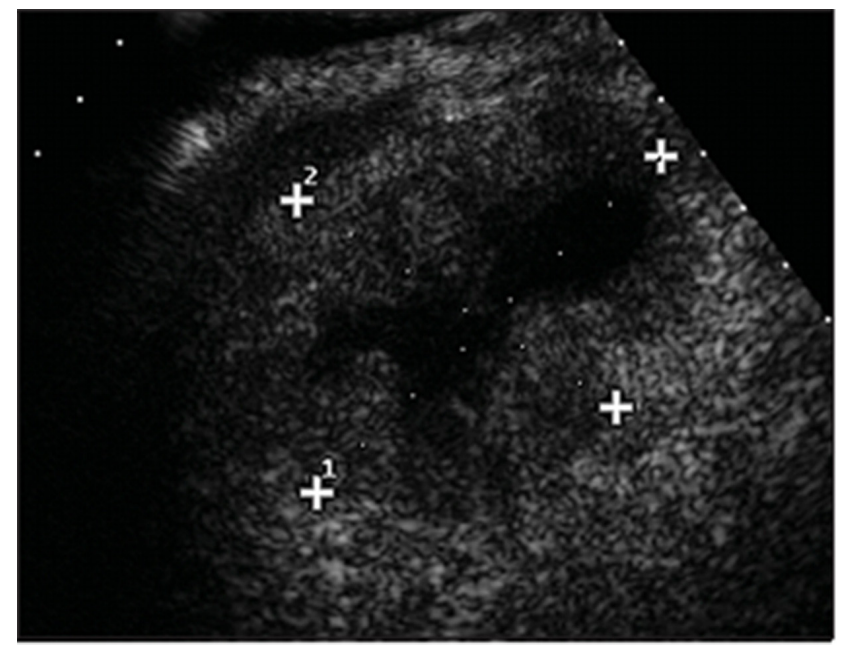

Figure 1: Right intercostal contrast-enhanced sonogram showing a $7 \mathrm{~cm} \times 6 \mathrm{~cm}$ colorectal metastasis of the right liver lobe

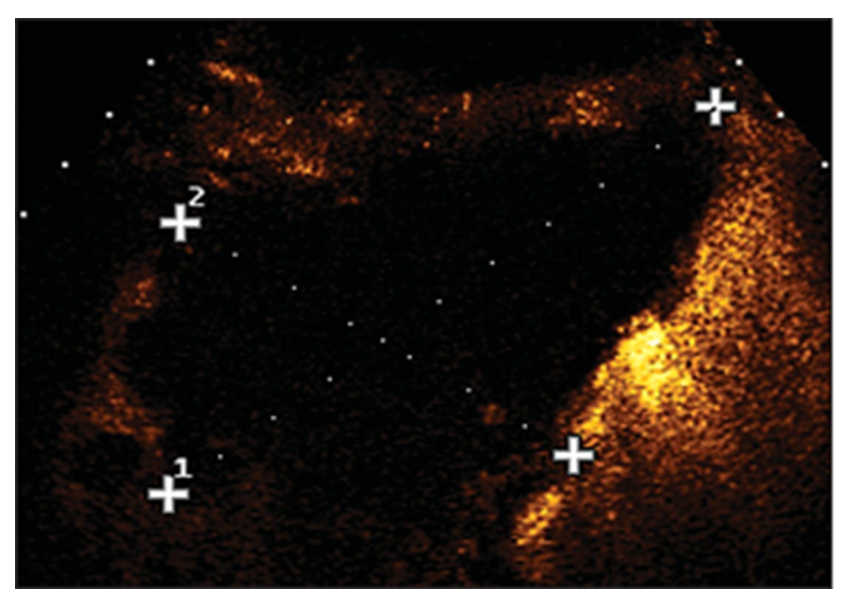

Figure 2: Right intercostal contrast-enhanced sonogram showing a $10 \mathrm{~cm} \times 7 \mathrm{~cm}$ ablation area produced after two insertions of a 14-gauge internally-cooled, minichoked MW antenna using a power output of $90 \mathrm{~W}$ for a total ablation time of $20 \mathrm{~min}$

power output. Indeed, we treated some HCCs and liver metastases measuring up to $7 \mathrm{~cm} \times 6 \mathrm{~cm}$, performing two insertions of a 14-gauge minichoked antenna and using a power output of $90 \mathrm{~W}$ for a total ablation time of $20 \mathrm{~min}$, achieving coagulation areas measuring up to $10 \mathrm{~cm} \times 7 \mathrm{~cm}$ [Figures 1 and 2].

Further randomized trials enrolling large series of patients are obviously needed to verify whether the superiority of MCT in obtaining larger ablation areas than RFA can translate into better long-term outcome and longer survival of patients with primary and secondary liver tumors, but it is indubitable that the technical improvement of MCT systems is already ongoing. According to the conclusion of the interesting review of Guan, ${ }^{[1]}$ we believe that MCT is leaving its infancy and is running up to a quite rosy future.

\section{Financial support and sponsorship}

Nil.

\section{Conflict of interest}

There is no conflict of interest.

\section{REFERENCES}

1. Guan YS. Microwave coagulation therapy of hepatocellular carcinoma. Hepatoma Res 2015;1:159-64.

2. Seki T, Wakabayashi M, Nakagawa T, Imamura M, Tamai T, Nishimura A, Yamashiki N, Okamura A, Inoue K. Percutaneous microwave coagulation therapy for patients with small hepatocellular carcinoma: comparison with percutaneous ethanol injection therapy. Cancer 1999;85:1694-702.

3. Horigome H, Nomura T, Saso K, Itoh M. Standards for selecting percutaneous ethanol injection therapy or percutaneous microwave coagulation therapy for solitary small hepatocellular carcinoma: consideration of local recurrence. Am J Gastroenterol 1999;94:1914-7.

4. Wang Y, Sun Y, Feng L, Gao Y, Ni X, Liang P. Internally cooled antenna for microwave ablation: results in ex vivo and in vivo porcine livers. Eur J Radiol 2008;67:357-61.

5. Ahmed M, Brace CL, Lee FT Jr, Goldberg SN. Principles of and advances in percutaneous ablation. Radiology 2011;258:351-69.

6. Cavagnaro M, Amabile C, Bernardi P, Pisa S, Tosoratti N. A minimally invasive antenna for microwave ablation therapies: design, performances, and experimental assessment. IEEE Trans Biomed Eng 2011;58:949-59.

7. Di Vece F, Tombesi P, Ermili F, Maraldi C, Sartori S Coagulation areas produced by cool-tip radiofrequency ablation and microwave ablation using a device to decrease back-heating effects: a prospective pilot study. Cardiovasc Intervent Radiol 2014;37:723-9.

8. Qian GJ, Wang N, Shen Q, Sheng YH, Zhao JQ, Kuang M, Liu GJ, Wu MC. Efficacy of microwave versus radiofrequency ablation for treatment of small hepatocellular carcinoma: experimental and clinical studies. Eur Radiol 2012;22:1983-90. 